\title{
AVALIAC̃̃̃O FÍSICO QUÍMICA DA CARNE DE JACARÉ-DO-PANTANAL (Caiman yacare DAUDIN 1802) DE IDADES DIFERENTES
}

\author{
Physichist chymistry evaluation of swampland alligator meat \\ (Caiman yacare Daudin 1802) of different ages \\ João Vicente Neto ${ }^{1}$, Maria Cristina Bressan ${ }^{2}$, Erika Cristina Rodrigues ${ }^{3}$, \\ Marco Antônio Kloster ${ }^{4}$, Merce Teodora Aguil Santana ${ }^{5}$
}

\begin{abstract}
RESUMO
Com o objetivo de avaliar a composição química e física da carne de jacaré-do-pantanal (Caiman yacare Daudin 1802), de idades diferentes, foram coletadas amostras de dois cortes de 10 jacarés-do-pantanal, sendo: 05 animais 14 meses e 05 animais com 26 meses, criados em cativeiro. Os cortes utilizados foram filé da cauda e filé do dorso. Foram determinados na composição química: umidade, proteína, extrato etéreo e cinzas; e na composição física: perda de peso por cozimento (PPC) e força de cisalhamento (FC). Houve interação $(\mathrm{P}<0,05)$ para umidade e para força de cisalhamento $(\mathrm{FC})$. Os animais com 14 meses apresentaram média de umidade mais elevada $(76,75 \%)$ no filé de cauda do que os animais de 26 meses $(74,48 \%)$. As médias de extrato etéreo variaram de: $0,40 \%$ a $0,54 \%$ entre os cortes para os animais de 14 meses e de $0,51 \%$ a $0,84 \%$ para os animais de 26 meses. Os valores de proteína encontrados foram: $23,57 \%$ no filé de cauda e $24,37 \%$ no filé de dorso nos animais de 14 meses; e de $24,26 \%$ no filé de cauda e $23,74 \%$ no filé de dorso para os animais de 26 meses. O valor médio da PPC nos animais com 14 meses foi maior (40,02\%), do que nos animais de 26 meses (33,82\%). As médias de FC foram maiores nos animais com 26 meses (4,47 kgf). O corte dorso apresentou médias superiores de FC $(3,81 \mathrm{kgf})$ em relação ao corte da cauda. Os animais abatidos com idade de 14 meses apresentaram carne mais macia e valores de extrato etéreo inferiores aos animais abatidos com 26 meses, demonstrando por estes parâmetros uma melhor qualidade física e química.
\end{abstract}

Termos para indexação: Animal silvestre, zoocriadouros, sustentabilidade.

\section{ABSTRACT}

With the objective of evaluating the chemical and physical composition of swampland alligator meat (Caiman yacare Daudin 1802), of different ages, samples of two courts of 10 swampland alligator were collected, being: 05 animals 14 months and 05 animals with 26 months, servants in captivity. The used courts were of tail and neck. They were certain in the chemical composition: moisture, protein, ethereal extract and ashes; and in the physical composition: weight loss for cooking (WLC) and break force (BF). There was interaction $(\mathrm{P}<0.05)$ for moisture and for break force $(\mathrm{BF})$. The animals with 14 months presented average of higher moisture (76.75\%) in the tail that the animals with 26 months (74.48\%). The averages of ethereal extract varied of: $0.40 \%$ to $0.54 \%$ among the courts for the animals of 14 months and of $0.51 \%$ to $0.84 \%$ for the animals of 26 months. The found protein values were: $23.57 \%$ in the tail and $24.37 \%$ in the neck in the animals of 14 months; and of $24.26 \%$ in the tail and $23.74 \%$ in the neck for the animals of 26 months. The medium value of WLC, in the animals with 14 months was larger $(40.02 \%)$, that in the animals of 26 months (33.82\%). The animals abated with age of 14 months presented softer meat and values of ethereal extract smaller the animals abated with 26 months, demonstrating for these parameters a better physical and chemical quality.

Index terms: Wild animal, captivity, maintainable.

\section{(Recebido em 20 de setembro de 2005 e aprovado em 2 de outubro de 2006)}

\section{INTRODUÇÃo}

A busca pelo uso e manejo sustentável de espécies silvestres brasileiras, vem se destacando ao longo dos anos. As experiências com criação em cativeiro de capivara (Hydrochaeris hydrochaeris) e jacaré-do-pantanal
(Caiman yacare) demonstram que se bem manejadas podem contribuir para o desenvolvimento econômico e ecológico de uma região. Segundo o Ibama (2002), como animais silvestres são considerados todas as espécies nativas, migratórias e quaisquer outras, aquáticas ou terrestres, que tenham todo ou parte de seu ciclo de vida

\footnotetext{
${ }^{1}$ Aluno de Doutorado no Departamento de Ciência dos Alimentos/DCA da Universidade Federal de Lavras/ UFLA - Cx. P. 3037 - $37200-000$ - Lavras, MG joaoviceneto@bol.com.br

${ }^{2}$ Médica Veterinária, Dra., Professora do Departamento de Ciência dos Alimentos/DCA da Universidade Federal de Lavras/UFLA - Cx. P. 3037 37200-000 - Lavras, MG - bressan@ufla.br

${ }^{3}$ Aluna de Mestrado no Departamento de Ciência dos Alimentos/DCA da Universidade Federal de Lavras/UFLA - Cx. P. 3037 - $37200-000$ - Lavras, MG UFLA - MG - grikabio@yahoo.com.br

${ }^{4}$ Zootecnista da Cooperativa de criadores de jacaré-do-pantanal - Av. Tannery, s/n - Cx. P. 15 - Distrito Industrial - 78200-000 - Cáceres, MT mkloster@brturbo.com.br

${ }^{5}$ Aluna de Doutorado no Departamento de Ciência dos Alimentos/DCA - Universidade Federal de Lavras/UFLA - Cx. P. 3037 - $37200-000$ - Lavras, MG mercesantana@yahoo.com.br
} 
ocorrendo dentro dos limites do território brasileiro, ou em águas jurisdicionais brasileiras.

O resultado do censo aéreo da população de jacarédo-pantanal, efetuado por Mourão (2004), demonstra que esta espécie não está ameaçada de extinção, como era suspeito, pois exibe uma população em torno de 150 indivíduos $/ \mathrm{km}^{2}$, distribuídos em todo o Pantanal. Esses dados embasaram a retirada do nome desta espécie da lista Norte-americana de espécies em extinção, permitindo a exportação de produtos e subprodutos do jacaré-dopantanal.

A criação racional de jacarés é uma atividade que vem se desenvolvendo ao longo de 15 anos, cujo objetivo principal é a obtenção de peles com melhor qualidade, ao contrário daquelas provenientes de animais capturados da natureza. Nesse sistema ocorre o aproveitamento integral do animal. Associada às novas leis ambientais, a exploração racional pode contribuir na manutenção do equilíbrio ecológico, desta espécie, no Pantanal Matogrossense, reduzindo a caça predatória (ALEIXO, 2000; MACIEL, 2001).

O consumo de carne de animais silvestre, no Brasil, vem aumentado nos últimos tempos e existe a demanda para a exportação. Por outro lado, a oferta desse produto é baixa e os índices de produção são flutuantes (SEBRAE, 2005). Além disso, as características nutricionais e físicas destas carnes são poucos conhecidas, o que inviabiliza a comercialização sistematizada, pois não atende às normas brasileiras de rotulagem e às exigências do mercado consumidor (VICENTE NETO, 2005).

Os primeiros estudos efetuados com carne de jacaré para consumo humano foram realizados por Moody et al. (1980), na Lousiana (Estados Unidos), com jacaré (Alligator mississippiensis), em que foram desenvolvidas técnicas para o abate, processamento e estudos da composição da carne em diferentes cortes do animal. Nesse estudo, foram avaliados quatro cortes de animais selvagens e os autores reportaram médias de proteínas totais variando de 21,1 a 22,3\%; umidade, 73 a 76,8\%; extrato etéreo, 1 a 1,5\%; e cinzas, 1 a 1,5\%. No Brasil, Romanelli (1995), estudando as propriedades tecnológicas da carne de jacaré-do-pantanal (Caiman yacare), com dois grupos de pesos diferentes (2 a $4 \mathrm{~kg}$ e 16,50 a $20,90 \mathrm{~kg}$ ), reportou médias para proteína de 18,40 a 18,43\%; umidade, 75,23 a 78,33\%; lipídeos totais, 2,25 a $5,32 \%$; e cinzas, 1,02 a $1,08 \%$, para as duas categorias de peso, respectivamente.

Objetivou-se com este estudo avaliar a qualidade físico-química da carne de jacaré-do-pantanal com diferentes idades.

\section{MATERIAL E MÉTODOS}

Foram utilizados 10 jacarés-do-pantanal (Caiman yacare Daudin 1802), sendo: 05 animais com peso vivo de 2,5 a $3 \mathrm{~kg}$, e idade de 14 meses e 05 animais com peso vivo de 5,0 a $6,0 \mathrm{~kg}$, e idade de 26 meses. Os animais foram criados em cativeiro autorizado pelo IBAMA no município de Cáceres - MT, onde eram alimentados com uma ração, em que a proteína animal é oriunda de uma mistura de vísceras bovinas moídas (pulmão e baço), farinha de sangue e farinha de carnes (ALEIXO, 2000; MACIEL, 2001).

Os animais no pré-abate, foram submetidos a jejum por 48 horas em tanques de alvenaria com água clorada a 5 ppm e posteriormente submetidos a lavagem superficial e encaminhados às instalações de abate (área de recepção e sala de matança). Os animais foram insensibilizados por pistola de dardo cativo disparado na região cranial e encaminhados para sangria, desmedulização, esfola, evisceração, lavagem da carcaça e posterior resfriamento em câmara de refrigeração à temperatura de 2 a $5{ }^{\circ} \mathrm{C}$, por 24 horas. As amostras, para as determinações de composição química e física, foram retiradas após 24 h post mortem. As porções dos músculos foram envolvidas em filme pvc, recobertas em papel alumínio, identificadas e congeladas a $-21^{\circ} \mathrm{C}$, em túnel de congelamento de ar forçado, e estocadas em câmara fria a $-18{ }^{\circ} \mathrm{C}$ até o momento do transporte para realização das análises. No momento das análises, as amostras foram descongeladas em câmara a $3,5 \pm 0,5{ }^{\circ} \mathrm{C}$.

Foram realizados os estudos nos cortes: filé de cauda e filé de dorso que correspondem aos músculos ílio-ischio-caudalis e occipito-cervicalis medialis, respectivamente (REESE, 2000). A determinação da composição química foi realizada em triplicata, segundo metodologia da AOAC (1995). Os parâmetros físicos de qualidade determinados foram: perda de peso por cozimento (PPC) e força de cisalhamento (FC). A determinação da PPC e FC foi realizada conforme descrição da AMASA (1978), pesadas em balança semi-analítica (Hobart-Dayton M 14239), embaladas em papel alumínio e cozidas em chapa a $150{ }^{\circ} \mathrm{C}$, até atingirem a temperatura interna de $72 \pm 2^{\circ} \mathrm{C}$. A diferença entre peso inicial e final das amostras correspondeu à perda de peso por cozimento. Para determinação da FC, foram retiradas 3 fatias das amostras advindas da PPC, de tamanho homogêneo $1 \mathrm{x} 1 \mathrm{x}$ $1 \mathrm{~cm}$, no sentido da fibra. A FC foi registrada em texturômetro, acoplado a uma probe Warner-Bratzler, numa escala variando de 0 a 10 (WHEELER \& KOOHMARAIE, 1994). Todas as análises foram realizadas em triplicata para maior confiabilidade nos resultados. 
$\mathrm{O}$ experimento foi conduzido em um delineamento inteiramente casualizado (DIC), em esquema fatorial $2 \times 2$, duas idades e dois cortes (cauda e dorso), com cinco repetições. Os dados obtidos foram analisados através do software estatístico SISVAR versão 4.0 (FERREIRA, 2000) com nível de significância de 5\%, e quando apresentada diferença significativa aplicou-se o teste de Tukey.

\section{RESULTADOS E DISCUSSÃO}

Houve diferença $(\mathrm{P}<0,05)$ entre os fatores corte $\mathrm{e}$ idade nos valores de umidade. Os animais com 14 meses apresentaram valores de umidade no corte cauda $(76,75 \%)$ superior aos dos animais de 26 meses $(74,48 \%)$. Esses dados confirmam os resultados clássicos que descrevem que animais mais jovens apresentam valores de umidade maiores do que animais mais velhos. $\mathrm{O}$ teor de umidade diminui com o aumento da idade, pois ocorre aumento na concentração de proteínas e gorduras, em função do crescimento (FORREST et al., 1979; PRÄNDL et al., 1994).
Nos valores de extrato etéreo, houve diferença $(\mathrm{P}>0,05)$ entre as idades e entre os cortes. Os animais de 14 meses apresentaram as médias mais baixas nos dois cortes estudados $(0,54$ e $0,40 \%$ para cauda e dorso, respectivamente). Isso justifica o valor de umidade mais elevado $(76,96 \%)$ encontrado nos animais de 14 meses. E, independente da idade, o corte cauda apresentou valores de extrato etéreo, mais elevado. Resultados semelhantes foram reportados por Vicente Neto (2005), que trabalhando com jacarés-do-pantanal oriundos de zoocriadouro e habitat natural, encontrou médias de $3,13 \%$ para o corte cauda e $0,51 \%$ para o corte dorso. A diferença para extrato etéreo relatado por Vicente Neto (2005) e os valores encontrados nesse trabalho podem ser justificados em função da idade entre os animais.

Os valores médios dos componentes da composição química, PPC e FC nos cortes de filé de dorso e filé de cauda de animais com idade de 14 e 26 meses encontramse na Tabela 1 .

TABELA 1 - Valores médios dos componentes da composição química, perda de peso por cozimento (PPC) e força de cisalhamento (FC) nos cortes de filé de dorso e filé de cauda de animais com idade de 14 e 26 meses. Cáceres/MT, 2005.

\begin{tabular}{|c|c|c|c|c|}
\hline \multirow{2}{*}{ Parâmetros analisados } & \multirow{2}{*}{ Idade } & \multicolumn{2}{|c|}{ Corte } & \multirow{2}{*}{ Média } \\
\hline & & Cauda & Dorso & \\
\hline \multirow{4}{*}{ Umidade (\%) } & 14 meses & $76,75^{\mathrm{aA}}$ & $77,18^{\mathrm{aA}}$ & 76,96 \\
\hline & 26 meses & $74,48^{\mathrm{bB}}$ & $76,06^{\mathrm{aB}}$ & 75,27 \\
\hline & Média & 75,61 & 76,62 & \\
\hline & $\mathrm{CV}(\%)$ & \multicolumn{2}{|c|}{0,79} & \\
\hline \multirow{4}{*}{ Proteína (\%) } & 14 meses & 23,57 & 24,37 & $23,97^{a}$ \\
\hline & 26 meses & 24,26 & 23,74 & $24,00^{\mathrm{a}}$ \\
\hline & Média & $23,91^{\mathrm{A}}$ & $24,06^{\mathrm{A}}$ & \\
\hline & $\mathrm{CV}(\%)$ & \multicolumn{2}{|c|}{4,27} & \\
\hline \multirow{4}{*}{ Extrato etéreo (\%) } & 14 meses & 0,54 & 0,40 & $0,47^{\mathrm{b}}$ \\
\hline & 26 meses & 0,84 & 0,51 & $0,67^{\mathrm{a}}$ \\
\hline & Média & $0,69^{\mathrm{a}}$ & $0,45^{\mathrm{b}}$ & \\
\hline & $\mathrm{CV}(\%)$ & \multicolumn{2}{|c|}{20,90} & \\
\hline \multirow{4}{*}{ Cinzas $(\%)$} & 14 meses & 0,54 & 0,82 & $0,70^{b}$ \\
\hline & 26 meses & 0,92 & 0,99 & $0,95^{\mathrm{a}}$ \\
\hline & Média & $0,75^{\mathrm{B}}$ & $0,91^{\mathrm{A}}$ & \\
\hline & $\mathrm{CV}(\%)$ & \multicolumn{2}{|c|}{17,87} & \\
\hline \multirow{4}{*}{$\mathrm{PPC}(\%)$} & 14 meses & 40,34 & 39,71 & $40,02^{\mathrm{a}}$ \\
\hline & 26 meses & 35,00 & 32,64 & $33,82^{\mathrm{b}}$ \\
\hline & Média & $37,67^{\mathrm{A}}$ & $36,13^{\mathrm{A}}$ & \\
\hline & $\mathrm{CV}(\%)$ & \multicolumn{2}{|c|}{4,67} & \\
\hline \multirow{4}{*}{ FC (kgf) } & 14 meses & $2,29^{\mathrm{aB}}$ & $2,50^{\mathrm{aB}}$ & 2,39 \\
\hline & 26 meses & $3,82^{\mathrm{bA}}$ & $5,11^{\mathrm{aA}}$ & 4,47 \\
\hline & Média & 3,05 & 3,81 & \\
\hline & $\mathrm{CV}(\%)$ & \multicolumn{2}{|c|}{11,95} & \\
\hline
\end{tabular}

Médias seguidas da mesma letra maiúscula na linha e minúscula na coluna não diferem entre si pelo teste de Tukey a $5 \%$ de significância. 
Miller et al. (1986) observaram que o aumento de gordura nos músculos é acompanhado pelo decréscimo de umidade. Em jacaré, resultado semelhante foi relatado por Romanelli (1995) em animais de dois grupos de pesos diferentes; sendo $75,23 \%$ de umidade e $5,32 \%$ de extrato etéreo, para animais de 16,5 a $20,9 \mathrm{~kg}$; e 78,33\% de umidade; 2,25\% de extrato etéreo, para animais de 2,0 a 4,0 kg.

Houve diferença $(\mathrm{P}<0,05)$ nos valores de cinzas entre as idades e os cortes em nosso estudo. Os animais com idade de 26 meses apresentaram a maior média de cinzas $(0,95 \%)$. O aumento no valor percentual de cinzas é observado nas diversas espécies animais, de acordo com o crescimento (FORREST et al., 1979). Parte do conteúdo mineral da carne se encontra associado a compostos orgânicos. Os sais inorgânicos permitem a manutenção da pressão osmótica das células, e participam também, em diversas funções metabólicas, como a contração muscular (PRÄNDL et al., 1994). Possivelmente, a maior média de cinzas encontrada nos animais de 26 meses se deve a maior movimentação exercida pelos mesmos no tanque, e conseqüente maior requerimento metabólico, do que os animais de 14 meses. Em jacaré-do-pantanal são reportados valores de cinzas de 1,02 a 1,08\% (ROMANELLI, 1995) e de 1,17 a $0,95 \%$ (VICENTE NETO, 2005). Em jacaré americano selvagem, Moody et al. (1980) reportam médias de 1,0 a $1,5 \%$.

Avaliando os valores obtidos para perda de peso por cozimento $(\mathrm{PPC})$, observa-se diferença $(\mathrm{P}<0,05)$ entre as idades. Os animais de 14 meses apresentaram as maiores perdas de peso. Isso pode ser explicado em função dos valores superiores de umidade, verificado nesse grupo de animais. Forrest et al. (1979) descreveram que a PPC em animais de açougue pode variar entre valores de $20 \%$ e $40 \%$. E além da composição química, outros fatores podem interferir nos resultados numa mesma espécie, tais como: diferentes metodologias de cocção (banho-maria ou chapa); preparo da amostra (retirada de tecidos conjuntivos e depósitos de gorduras) e as categorias de pesos ao abate, em que os animais apresentam diferentes percentuais de gordura na carcaça (SOUZA, 2001).

Nesse estudo, as médias de PPC variaram de 32,64 a 40,34\%. Em jacaré-do-pantanal, Araújo et al. (2004) reportam entre 39,71 a 40,34\%, nos diversos cortes estudados. Em animais silvestres como capivara são reportados valores de 32,27\% por Jardim (2001) e de 29,87\% por Miguel (2002) no músculo longissimus dorsi.

Houve interação entre os fatores cortes e idade nos valores de força de cisalhamento $(\mathrm{P}<0,05)$. Os animais com 14 meses apresentaram valores mais baixos de FC
(2,39 kgf), quando comparados com os animais de 26 meses $(4,47 \mathrm{kgf})$. Isso normalmente é explicado em virtude de animais mais jovens apresentarem em sua composição menor proporção de tecido conectivo. E segundo Bickerstaffe et al. (1997), a carne é classificada como macia, quando a FC atinge valores de até $8 \mathrm{kgf}$; é considerada aceitável quando esses valores estão entre 8 kgf e 11 kgf; e passa a ser considerada dura com valores acima de $11 \mathrm{kgf}$.

Independente da idade, o corte cauda apresentou média mais baixa de FC (3,05 kgf), quando comparado com o corte dorso $(3,81 \mathrm{kgf})$. Isso demonstra que o corte cauda é mais macio. Em jacarés-do-pantanal, resultados semelhantes foram encontrados por Vicente Neto (2005), sendo que as médias de FC foram de 3,92 kgf para cauda e $5,20 \mathrm{kgf}$ para dorso. Jardim (2001), em capivara, relatou valores de 4,94 a 5,50 kgf; e Miguel (2002) reportou valores de $5,16 \mathrm{kgf}$.

\section{CONCLUSÃO}

Os animais abatidos com idade de 14 meses apresentam as melhores características de qualidade física e química do que os animais abatidos com 26 meses.

\section{AGRADECIMENTOS}

Os autores agradecem a Cooperativa de Criadores de Jacaré-do-pantanal pela disponibilização das amostras.

\section{REFERÊNCIAS BIBLIOGRÁFICAS}

ALEIXO, V. M. Efeitos do uso de farelo de soja e de sistemas de alimentação sobre o desempenho de filhotes de jacarédo-pantanal Caiman yacare (Daudin, 1802). 2000. 92 p. Dissertação (Mestrado em Zootecnia) - Universidade Federal de Lavras, Lavras, 2000.

\section{AMASA. Guidelines for cooking and sensory evaluation of meat. Chicago, 1978.}

ARAÚJO, L. C.; FERRÃO, S. B. P.; RODRIGUES, E. R.; BRESSAN, M. C.; FARIA, P. B.; VIEIRA, J. O.; VICENTE NETO, J. Cor, perda de peso por cozimento e força de cisalhamento da carne de jacaré-do-pantanal (Caiman yacare Daudin 1802) oriundos de zoocriadouros. In: CONGRESSO DE PÓS GRADUAÇÃO DA UFLA-MG, 13., 2004, Lavras. Anais... Lavras: UFLA, 2004. p. 78-82.

ASSOCIATION OF OFFICIAL ANALYTICAL CHEMISTS. Official methods of analysis of the Association of Official Analytical Chemists. 16. ed. Arlington, 1995. 
BICKERSTAFFE, R.; LE-COUTER, C. E.; MORTON, J. D. Consistency of tenderness in New Zealand retail meat. In: INTERNACIONAL CONGRESS OF MEAT SCIENCE AND TECHNOLOGY, 43., 1997, Auckland. Anais... Auckland: ICOMST, 1997.

FERREIRA, D. F. Análises estatísticas por meio do Sisvar para o Windows versão 4.0. In: REUNIÃO ANUAL DA REGIÃO BRASILEIRA DA SOCIEDADE INTERNACIONAL DE BIOMETRIA, 45., 2000, São Carlos. Anais... São Carlos: UFSCar, 2000. p. 255-258.

FORREST, J. C.; ABERLE, E. D.; HEDRICK, H. B.; JEDGE, M. D.; MERKEL, R. A. Fundamentos de ciencia de la carne. Zaragoza: Acribia, 1979. 364 p.

IBAMA. Centro de Conservação e Manejo de Répteis e Anfíbios. Projeto jacaré-do-pantanal. Brasília, DF: Ministério do Meio Ambiente; IBAMA-RAN, 2002.

JARDIM, N. S. Sexo e diferentes pesos ao abate na qualidade da carne de capivara (Hydrochaeris hydrochaeris L. 1766). 2001. 119 p. Dissertação (Mestrado em Ciência de Alimentos) - Universidade Federal de Lavras, Lavras, 2001.

MACIEL, F. R. Coeficiente de digestibilidade aparente de cinco fontes energéticas para o jacaré-do-pantanal (caiman yacare, Daudin, 1802). 2001. 76 p. Dissertação (Mestrado em Zootecnia) - Universidade Federal de Lavras, Lavras, 2001.

MIGUEL, G. Z. Caracterização da carcaça e da carne de capivaras (Hydrochaeris hydrochaeris L. 1766) em idade adulta. 2002. 107 p. Dissertação (Mestrado em Ciência de Alimentos) - Universidade Federal de Lavras, Lavras, 2002.

MILLER, G. J.; FIELD, R. A.; RILEY, M. L.; WILLIAMS, J. C. Lipids in wild ruminant animals and steers. Journal Food Quality, Wastport, v. 9, p. 331-343, 1986.

MOODY, M.; COREIL, P. D.; RUTLEDGE, J. E Alligator meat: yields, quality studied. Lousiana Agriculture, [S.1.], v. 24 , n. 1 , p. $14-15,1980$.
MOURÃO, G. M. Utilização econômica da fauna silvestre no Brasil: o exemplo do jacaré-do-pantanal. Disponível em: <http://www.cpap.embrapa.br/publicacoes/online/ ADM05>. Acesso em: 3 jun. 2004.

PRANDL, O.; FISCHER, A.; SCHMIDHOFER, T.; SINELL, H. J. Tecnologia e higiene de la carne. Zaragoza: Acríbia, 1994. $854 \mathrm{p}$

REESE, A. M. The alligator and its allies. Landisville: Arment Biological, 2000. 229 p. Disponível em: <www.herper.com/ebooks/>. Acesso em: 3 jun. 2004.

ROMANELLI, P. F. Propriedades tecnológicas da carne do jacaré do pantanal caiman Crocodilus Yacare (Daudin, 1802). 1995. 110 f. Tese (Doutorado em Tecnologia de Alimentos) - Universidade Estadual de Campinas, Campinas, 1995.

SERVIÇO BRASILEIRO DE APOIO A MICRO E PEQUENAS EMPRESAS. Diagnóstico da cadeia produtiva do jacaré-do-pantanal (Caiman yacare) no estado de Mato Grosso. In: PROJETO ARRANJO PRODUTIVO LOCAL JACARÉ-DO-PANTANAL, 1., 2005, Cáceres. Workshop... Cáceres: [s.n.], 2005.

SOUZA, X. R. Efeitos de grupo genetico, sexo e peso ao abate na qualidade de carne de cordeiros em crescimento. 2001. 116 p. Dissertação (Mestrado em Ciência dos Alimentos) - Universidade Federal de Lavras, Lavras, 2001.

VICENTE NETO, J. Caracterização físico química, colesterol e ácidos graxos da carne de jacaré-do-pantanal (Caiman yacare Daudin 1802) oriundo de zoocriadouro e habitat natural. 2005. 122 p. Dissertação (Mestrado em Ciência dos Alimentos) - Universidade Federal de Lavras, Lavras, 2005

WHEELER, T. L.; KOOHMARAIE, M. Prerigor and postrigor changes in tenderness of ovine longissimus muscle. Journal of Animal Science, Champaign, v. 72, n. 5, p. 1232-1238, May 1994. 